\title{
EFFECT OF TOOTHBRUSH ABRASION ON SURFACE ROUGHNESS OF DEMINERALIZED ENAMEL TREATED WITH RESIN INFILTRATION
}

\author{
Ahmed Fawzy* and Shereef S. Abdellateef **
}

\begin{abstract}
This study was conducted to evaluate the effect of the toothbrush abrasion on surface roughness of the demineralized enamel treated with resin infiltration.

Materials and methods: A total number of 12 extracted caries-free human permanent premolars were used in this study. Surface roughness assessment of specimens (sound enamel) was performed using Environmental Scanning Electron Microscope $\left(\mathrm{R}_{1}\right)$. Specimens were subjected to a demineralization protocol until a white spot lesion (WSL) was developed (chalky white lesion) (surface roughness $\mathrm{R}_{2}$ ). Resin infiltrant was applied on the WSL $\left(\mathrm{R}_{3}\right)$, followed by tooth brush abrasion $\left(R_{4}\right)$. Surface roughness assessment of specimens $(R)$ was performed qualitatively and quantitatively using Environmental Scanning Electron Microscope for each of the four stages of the study.
\end{abstract}

Results: One-way ANOVA showed statistical significant difference between the tested groups $(\mathrm{P}=0.001)$. The post-hoc test revealed that sound enamel has significantly the lowest surface roughness than all other tested groups $(\mathrm{P}=0.001)$. Moreover, demineralized enamel and toothbrush abraded resin infiltrated enamel had significantly lower surface roughness than that of resin infiltrated enamel $(\mathrm{P}=0.001)$. No significant differences were revealed between demineralized enamel and toothbrush abraded resin infiltrated enamel $(\mathrm{P}=0.309)$.

Conclusions: Within the limitations of the study, it can be concluded that: 1- Surface roughness of enamel with artificial carious lesion treated with resin infiltration was higher than that of sound enamel. 2- Tooth brushing have the potential to lower the surface roughness of artificial carious lesion treated with resin infiltration.

\section{INTRODUCTION}

Non invasive treatment protocols are of the main focus points of conservative dentistry nowadays. Several attempts have been made to stop the progress of an incipient enamel lesion, increasing tissue preservation and preventing cavitation of the dental structure. Assessment of the therapeutic effect provided by these attempts has been made under various settings. Microabrasion ${ }^{(1-3)}$ and resin infiltration ${ }^{(4-8)}$ methods were reported to produce

Lecturer of Operative Dentistry, Suez Canal University

** Lecturer of Pediatric Dentistry, Suez Canal University 
satisfactory results in shorter time intervals, compared with remineralization using fluoride or amorphous calcium phosphate derivatives.

Resinous infiltration, and occlusion of early lesion's micro-spaces \& micro-porosities with a low viscosity resin obstructing the inward diffusion pathway for acids ${ }^{(9-13)}$ and outward flow of dissolved minerals at an early caries development stage was one of the promising lines of treatment that was developed in the past ten years and now introduced in markets. ${ }^{(14-23)}$

Today resin infiltration is considered as a well known treatment regimen related to minimal intervention dentistry ${ }^{(24)}$. It was noticed that producing a barrier on top of the lesion was not as important as fully occupying the inner space with resin to prevent progression ${ }^{25)}$. Low viscosity resinous materials provided attainable depth of penetration and ability of arresting the progression of caries, several surface treatments and time of application have been proposed by several studies ${ }^{(9,11)}$.

Compared to artificial caries-like lesions, natural lesions have rather more complex microstructural patterns. Yet artificial caries-like lesions have the advantage that they can be produced under standardized reproducible conditions ${ }^{(26)}$.

Surface roughness of the resin infiltrated incipient enamel lesion is one of the major determinant of long term prognosis of the line of treatment, as the produced roughness may facilitate plaque buildup, encouraging demineralization and development of secondary carious lesion. Therefore, the surface roughness resulting from toothbrush abrasion of resin infiltration treatment is important for evaluation, of the long term prognosis of the line of treatment.

Furthermore, no information is available on how resistant these treated surfaces will be against toothbrush abrasion, a challenge that tooth surface faces on regular bases. Therefore, the aims of this study were to evaluate the effect of tooth toothbrush abrasion on surface roughness of demineralized enamel treated with resin infiltration.

\section{MATERIALS AND METHODS}

A total number of 12 extracted caries-free human permanent premolars were used in this study. Teeth were washed with water, scaled with periodontal scalar to remove any blood, attached periodontal tissues, plaque and calculus. Teeth were then stored in $0.1 \%$ Thymol solution at room temperature till the time of their use. The buccal surface of each tooth was covered by an acid-resistant nail varnish (Maybelline Ultra Lasting; Gemey-Maybelline, Paris, France) leaving only a window of $2 \mathrm{~mm} \times 2 \mathrm{~mm}$ in the middle/middle of the buccal surface. ${ }^{(27)}$

Baseline: Surface roughness was measured for the sound enamel surface

Demineralization: The initial erosion lesion was obtained in vitro by immersing the specimens in citric acid solution $(0.30 \mathrm{~mol} / \mathrm{L}, \mathrm{pH} 2)$ for $60 \mathrm{~min}$, at room temperature $(25 \mathrm{C})$, until a white spot lesion (chalky white lesion) was developed. After that the teeth were rinsed using air water spray for 1 minute to ensure washing all remnants.

Surface roughness was measured for the demineralized enamel surface

Resin infiltration by Icon system: Application of Icon [Tab.(1)], as recommended by manufacturer. Surface roughness was measured for the resin infiltrated enamel surface

Toothbrush abrasion: The samples were subjected to toothbrush abrasion using a toothbrushing machine with horizontal movements of the toothbrush under a weight of $0.2 \mathrm{~kg}$ and a traveled course of $3.8 \mathrm{~cm}$. The rotation was of 240 cycles/min, the total time of tooth brushing was of $100 \mathrm{~min}$, so total cycles were 24000 cycles. Toothbrush head was replaced with every new sample, while a slurry mixture was applied every 5 minutes of the testing time. ${ }^{(28)}$

Surface roughness was measured for the treated enamel surface after toothbrush abrasion. 
TABLE (1) Material used, manufacture, composition and steps of application

\begin{tabular}{|c|c|c|c|}
\hline Material & Manufacture & Composition & Application \\
\hline \multirow{3}{*}{ ICON } & \multirow{3}{*}{$\begin{array}{l}\text { DMG (Hamburg, } \\
\text { Germany) }\end{array}$} & $\begin{array}{l}\text { Icon-Etch: hydrochloric acid Salicylic pyrogenic acid. } \\
\text { Surface- active substances. }\end{array}$ & Applied for $120 \mathrm{~s}$. \\
\hline & & Icon-Dry: $99 \%$ ethanol. & Applied for $30 \mathrm{~s}$ with air drying. \\
\hline & & $\begin{array}{l}\text { Icon-Infiltrant: TEGDMA-based resin, initiators and } \\
\text { additives. }\end{array}$ & $\begin{array}{l}\text { Applied for } 180 \mathrm{~s} \text {, } \\
\text { reapplied for } 60 \mathrm{~s} \text {, cured for } 40 \mathrm{~s}\end{array}$ \\
\hline
\end{tabular}

\section{Surface roughness measurements and Statistical Analysis:}

Surface roughness assessment of specimens was performed qualitatively and quantitatively using Environmental Scanning Electron Microscope. Base line $\left(R_{1}\right)$, demineralized $\left(R_{2}\right)$, infiltrated $\left(R_{3}\right)$ and toothbrush abraded $\left(\mathrm{R}_{4}\right)$ stages of the enamel surface were recorded and tabulated. Data were subjected to the statistical analysis.

\section{RESULTS}

ESEM three dimensional image of the tested enamel surfaces are represented in the Fig (1) where (a) showing minimal surface roughness of sound enamel surface, (b) showing increased surface roughness enamel surface as a result of demineralization, (c) resin infiltrated enamel and (d) toothbrush abraded resin infiltrated enamel.

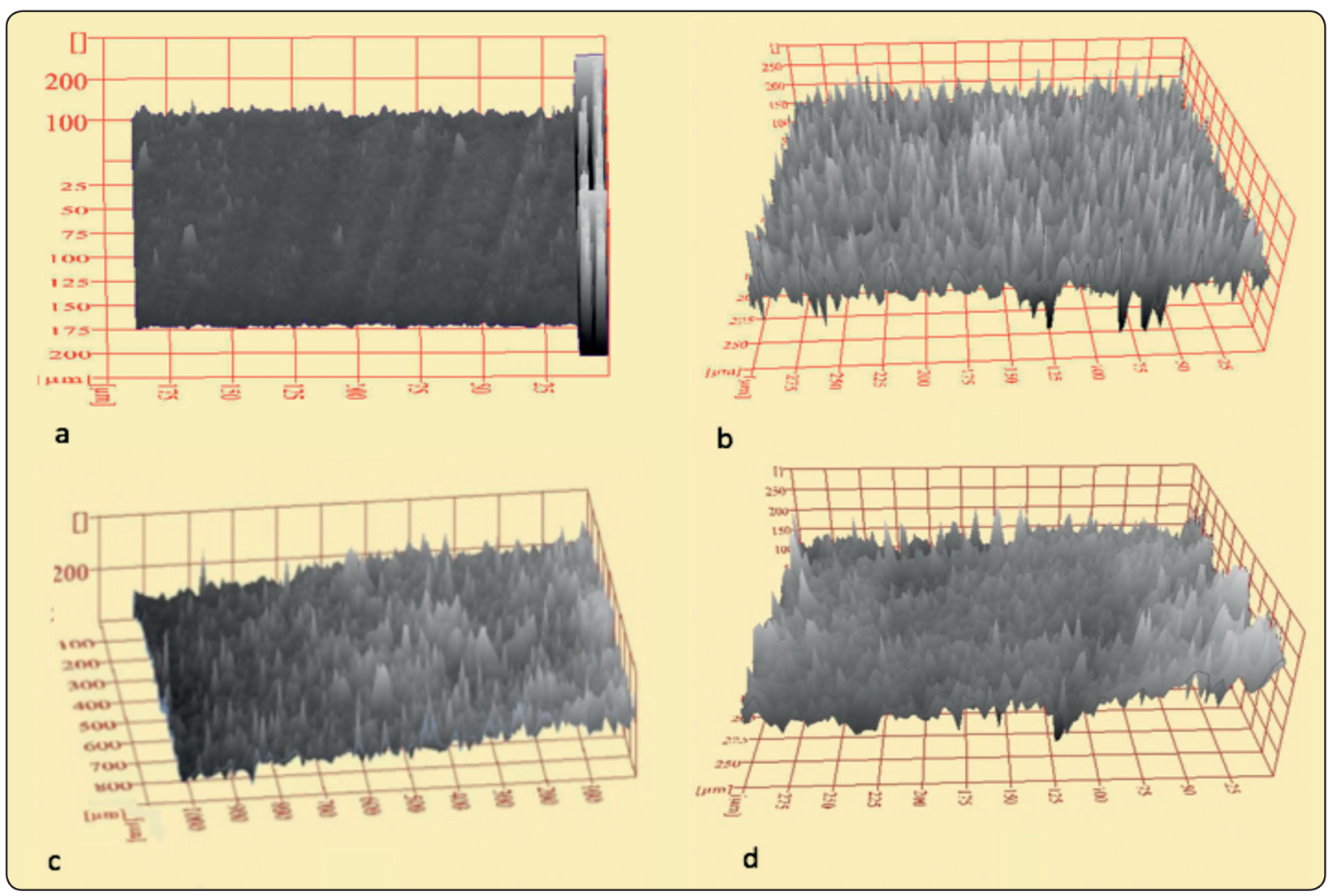

Fig. (1) Three dimensional image of the tested enamel surfaces. (a) sound enamel surface $\left(R_{1}\right)$. (b) demineralized enamel surface $\left(R_{2}\right)$. (c) resin infiltrated enamel $\left(R_{3}\right)$ and $(d)$ toothbrush abraded resin infiltrated enamel $\left(R_{4}\right)$. 
The Mean enamel surface roughness and standard deviation of values are described in Table (2) \& Fig (2). One-way ANOVA showed statistical significant difference $(\mathrm{P}=0.001)$. The post-hoc test revealed that sound enamel has significantly the lowest surface roughness than all other tested groups $(\mathrm{P}=0.001)$. Moreover, demineralized enamel and toothbrush abraded resin infiltrated enamel had significantly lower surface roughness than that of resin infiltrated enamel $(\mathrm{P}=0.001)$. No significant differences were revealed between demineralized enamel and toothbrush abraded resin infiltrated enamel $(\mathrm{P}=0.309)$.

TABLE (2) Mean and standard deviation of enamel surface roughness

\begin{tabular}{lcc}
\hline \multicolumn{1}{c}{ Tested Enamel surface } & Mean In $\mu \mathrm{m}$ & Standard Deviation \\
\hline Sound Enamel $\left(\mathrm{R}_{1}\right)$ & $135.3033^{(\mathrm{a})}$ & 9.30577 \\
\hline Demineralized Enamel $\left(\mathrm{R}_{2}\right)$ & $185.6667^{(\mathrm{b})}$ & 6.28611 \\
\hline Resin Infiltrated Enamel $\left(\mathrm{R}_{3}\right)$ & $198.9433^{(\mathrm{c})}$ & 6.17029 \\
\hline Toothbrush abraded Resin Infiltrated Enamel $\left(\mathrm{R}_{4}\right)$ & $182.6667^{(\mathrm{b})}$ & 6.28611 \\
\hline
\end{tabular}

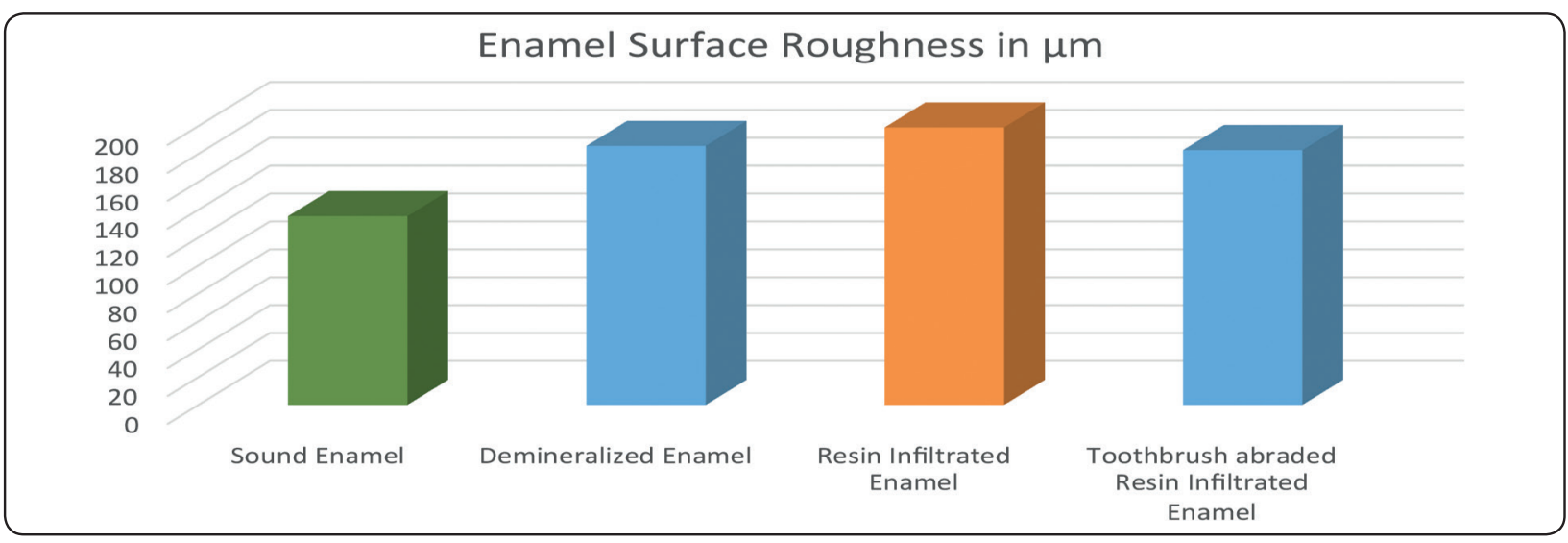

Fig. (2) Mean enamel surface roughness in micrometers

\section{DISCUSSION}

Surface roughness of enamel incipient lesions plays a significant role in increasing the rate of plaque accumulation, maturation and retention, which has a drastic effect on caries and periodontal inflammation risk, and could also contribute to extrinsic staining of teeth. ${ }^{(29)}$

Homogenously infiltrating the demineralized defect using a low viscosity resinous material would be beneficial in breaking the caries cycle.
But leaving a resinous layer over the lesion could deprive the procedure from it's main goal as it will add to the surface roughness of the substrate, offering retentive sites for plaque and hence increasing caries risk. ${ }^{(30,31)}$

The ESEM results [Fig. (1)] revealed that the infiltrate applied to the demineralized enamel surface had appeared to be projecting from the surface. Those observations might explain the recorded surface roughness values of enamel when 
treated with resin infiltrate. However, surface roughness has dropped significantly when exposed to toothbrush abrasion which may be attributed to the wear of the resinous layer covering the enamel surface leaving the infiltrated lesion exposed.

Although the resin infiltrate is able to occupy the space within the body of the lesion, the resin infiltrated enamel surface is characterized by the presence of holes and column gaps amongst cured resin material signifying poorly infiltrated mineral phase. Also clearly obvious feature for the infiltrated enamel was the presence of a thick coating layer of resin above the lesion. ${ }^{(32)}$ Irregular surface profiles were common in other studies ${ }^{(20,23)}$ for the infiltrated lesions and they owed this to peeling and blistering of the resin-covering layer. They also detected Macroscopic voids, that might arise from natural enamel cracks that are present in human enamel. However, the artificial demineralization process using the citric acid might preferably demineralize along those enamel pre-cracks, thereby creating larger voids. Large voids are less prominent in natural lesions. However, once they are present it is difficult for a low-viscosity (and therefore highly shrinking) resin infiltrate to fill and bridge those large gaps.

The pre-treatment in citric acid solution could have influenced our findings, increasing the enamel dissolution and, consequently, changing its surface roughness. Belli et al. ${ }^{(25)}(2011)$ have also observed that bovine enamel has macroscopic-sized voids that can accelerate the caries process, thereby acting as an obstacle against proper resin infiltration. Therefore, the enamel can present demineralized zones unfilled by the infiltrating resin, increasing surface roughness

The surface changes after brushing may be attributed to the loss of the low wear resistant resin layer that remains on the top of the enamel surface ${ }^{(33)}$, such loss may have been aggravated by the presence of oxygen inhibited polymerization surface layer of resin infiltrate due to the inability of TEGDMA to hinder air diffusion as efficiently as other high viscosity monomers, that drastically affects surface properties of resin infiltrate. ${ }^{(34)}$

After resin infiltration a mild significance was detected in surface roughness which is in accordance with the results of Yuan et al. ${ }^{(35)}$ (2013), who recommended the polishing of the infiltrated surface. Which also can explain the performance of the infiltrated surface after tooth brushing.

\section{CONCLUSIONS}

Within the limitations of the study, it can be concluded that:

1- Surface roughness of enamel with artificial carious lesion treated with resin infiltration was higher than that of sound enamel.

2- Tooth brushing have the potential to lower the surface roughness of artificial carious lesion treated with resin infiltration.

\section{REFERENCES}

1. Murphy T C, Willmot D R, Rodd H D 2007 Management of postorthodontic demineralized white lesions with microabrasion: a quantita- tive assessment. American Journal of Orthodontics and Dentofacial Orthopedics 131: 27-33

2. Neuhaus K W, Ciucchi P, Donnet M, Lussi A 2010 Removal of enamel caries with an air abrasion powder. Operative Dentistry 35: 538-546

3. Pliska B T, Warner G A, Tantbirojn D, Larson B E 2012 Treatment of white spot lesions with ACP paste and microabrasion. The Angle Orthodontist 82: 765-769

4. Kielbassa A M, Muller J, Gernhardt C R 2009 Closing the gap between oral hygiene and minimally invasive dentistry: a review on the resin infiltration technique of incipient (proximal) enamel lesions. Quintessence International (Berlin, Germany: 1985) 40: 663-681

5. Hammad S M, El Banna M, El Zayat I, Mohsen M A 2012 Effect of resin infiltration on white spot lesions after debonding orthodontic brackets. American Journal of Dentistry $25: 3-8$

6. Torres CRG, Borges A B, Torres L M, Gomes I S, de Oliveira R S 2011 E ect of caries in ltration technique and uoride therapy on the colour masking of white spot lesions. Journal of Dentistry 39: 202-207 
7. Kim Y, Son H H, Yi K, Kim H Y, Ahn J, Chang J 2013 The color change in arti cial white spot lesions measured using a spectroradiometer. Clinical Oral Investigations 17: 139-146

8. Soviero V M, Paris S, Leal S C, Azevedo R B, MeyerLueckel H 2013 Ex vivo evaluation of caries in ltration after di erent application times in primary molars. Caries Research 47: 110-116

9. Meyer-Lueckel H, Paris S, Mueller J, Colfen H, Kielbassa AM. Influence of the application time on the penetration of different dental adhesives and a fissure sealant into artificial subsurface lesions in bovine enamel. Dent Mater. 2006;22:22-8. [PubMed]

10. Schmidlin PR, Zehnder M, Pasqualetti T, Imfeld T, Besek MJ. Penetration of a bonding agent into De- and remineralized enamel in vitro. J Adh Dent. 2004;6:111-5. [PubMed]

11. Gray GB, Shellis P. Infiltration of resin into white spot caries-like lesions of enamel an in vitro study. Eur J Prosthodont Restor Dent. 2002;10:27-32. [PubMed]

12. Robinson C, Hallsworth AS, Weatherell JA, Kunzel W. Arrest and control of carious lesions A study based on preliminary experiments with resorcinol-formaldehyde resin. J Dent Res. 1976;55:812-8. [PubMed]

13. Davila JM, Buonocore MG, Greeley CB, Provenza DV. Adhe-sive penetration in human artificial and natural white spots. J Dent Res. 1975;54:999-1008. [PubMed]

14. Meyer-Lueckel H, Bitter K, Paris S. Randomized controlled clinical trial on proximal caries infiltration ThreeYear Fol-low-Up. Caries Res. 2012;46:544-8. [PubMed]

15. Paris S, Bitter K, Naumann M, Dorfer CE, Meyer-Lueckel H. Resin infiltration of proximal caries lesions differing in ICDAS codes. Eur J Oral Sci. 2011;119:182-6. [PubMed]

16. Paris S, Hopfenmuller W, Meyer-Lueckel H. Resin infiltration of caries lesions an efficacy randomized trial. J Dental Res. 2010;89:823-6. [PubMed]

17. Paris S, Meyer-Lueckel H. Infiltrants inhibit progression of natural caries lesions in vitro. J Dent Res. 2010;89:127680. [PubMed]

18. Paris $\mathrm{S}$, Meyer-Lueckel H. Inhibition of caries progression by resin infiltration in situ. Caries Res. 2010;44:47-54. [PubMed]

19. Meyer-Lueckel H, Paris S. Infiltration of natural caries lesions with experimental resins differing in penetration coefficients and ethanol addition. Caries Res. 2010;44:40814. [PubMed]
20. Meyer-Lueckel H, Paris S. Progression of artificial enamel caries lesions after infiltration with experimental light curing resins. Caries Res. 2008;42:117-24. [PubMed]

21. Meyer-Lueckel H, Paris S. Improved resin infiltration of natural caries lesions. J Dental Res. 2008; 87:1112-6. [PubMed]

22. Paris S, Meyer-Lueckel H, Colfen H, Kielbassa AM. Penetra-tion coefficients of commercially available and experimental composites intended to infiltrate enamel carious lesions. Dental Mater. 2007;23:742-8. [PubMed]

23. Paris S, Meyer-Lueckel H, Kielbassa AM. Resin infiltration of natural caries lesions. J Dent Res. 2007; 86:662-6. [PubMed].

24. Kielbasa AM, Müller J, Gernhardt CR. Closing the gap between oral hygiene and minimally invasive dentistry: a review on the resin infiltration technique of incipient (proximal) enamel lesions. Quintessence Int 2009; 40: 663-81.

25. Belli R, Rahiotis C, Schubert EW, Baratier LN, Petschelt A, Lohbauer U. Wear and morphology of infiltrated white spot lesion. Journal of dentistry, Vol.39, Issue 5, May 2011, Pages 376-385.

26. Yang B, Flaim G, Dickens SH. Remineralization of human natural caries and artificial caries-like lesions with an experimental whisker-reinforced ART-composite. Acta Biomater. 2011 May; 7(5): 2303-2309.

27. Neuhaus K.W. Schlafer S., Lussi A., Nyvad B. Infiltration of Natural Caries Lesions in Relation to Their Activity Status and Acid Pretreatment in vitro Caries Res 2013;47:203-210

28. Tanoue N, Matsumura H. , and Atsuta M. Wear and surface roughness of current prosthetic composites after toothbrush/dentifrice abrasion. July 2000Volume 84 , Issue 1 , Pages 93-97

29. Rahardjo A, Gracia E, Riska G, Adiatman M, Maharani DA Potential Side Effects of Whitening Toothpaste on Enamel Roughness and Micro Hardness Int J Clin Prev Dent 2015;11(4):239-242

30. Mueller J., Meyer-Lueckel H., Paris S., Kielbassa A.M. Inhibition of lesion progression by penetration of resins in vitro: influence of the application procedure. Oper. Dent. 2006; 31:338-345. [PubMed]

31. Paris S., Meyer-Lueckel H., Mueller J., Hummel M., Kielbassa A.M. Progression of sealed initial bovine enamel lesions under demineralising conditions in vitro. Caries Res. 2006;40:129 [ubMed] 
32. Tostes MA, Santos Jr E, Camargo Jr SA Effect of resin infiltration on the nanomechanical properties of demineralized bovine enamel Indian Journal of Dentistry I September 2014 | Vol 5 | Issue 3

33. Taher NM, Alkhamis HA, Dowaidi SM. The influence of resin infiltration system on enamel microhardness and surface roughness: An in vitro study. Saudi Dent J. 2012 Apr; 24(2): 79-84.
34. Rahiotis C., Zinelis S., Eliades G., Eliades T. Setting characteristics of a resin infiltration system for incipient caries treatment. Journal of dentistry 43 (2015) 715-719

35. Yuan CQ, Dou GW, Deng J, Geng GL, Sun P, Cao YX. Effect of infiltration technique and polishing on the roughness of artificial carious enamel surfaces]. Shanghai Kou Qiang Yi Xue. 2013 Aug; 22(4):402-6. 